\title{
Intranasal Splint in Nasal Septal Surgery: Is It Necessary?
}

\author{
Jahangir Alam Mazumder*1, Md. Golam Mustafa², AHM Delwar ${ }^{3}$, \\ Shazibur Rashid ${ }^{4}$, Md. Mostafizur Rahaman ${ }^{5}$, Shamsuddin Ahmed ${ }^{6}$
}

\begin{abstract}
Introduction: After SMR/septoplasty with or without turbinate surgery, it needs to keep apart the septum and turbinates up to their complete healing otherwise there is a chance of adhesion (synechia) formation. To prevent this there are various procedures. To place an intranasal splint in one or both sides of the septum is one of them. Nowadays there raised the question of whether the splinting is necessary or not. There is no significant difference in result with or without an intranasal splint. Weighing against the co-morbidities the routine use of an intranasal splint can no longer be justified. Materials and Methods: This is a randomized control study of 200 patients of SMR/septoplasty, done for nasal septal deviation causing symptoms in Cumilla Medical College Hospital in the period of January 2016 to December 2019. They were equally divided into two groups, group-A were operated placing an intranasal splint and group-B with no intranasal splint. They were followed up for 6 weeks to detect any synechia and co-morbidities. Result: The age of our patients was ranged from 13-49 years with a mean age of 22.45 years. The male to female ratio is 1.78:1. Synechia was found in $4 \%$ of the splinted group and 6 of the nonsplinted groups. Co-morbidities were detected more in the splinted group than that of non-splinted. In INS group these were found as follows: pain in the nose, face and head (26\%), faint during removal of nasal splint (6\%), nasal obstruction (38\%), the anxiety of splint removal in the postoperative period (35\%) and vestibulitis due to persistent irritation by a splint (17\%). Conclusion: There is little significant advantage of using intranasal splint routinely in septal surgery to prevent synechia formation.

Keywords: Intranasal splint, Synechia, SMR, Septoplasty.

Number of Tables: 04; Number of Figures: 01; Number of References: 20; Number of Correspondence: 03.
\end{abstract}

*1. Corresponding Author:

Dr. Jahangir Alam Mazumder

Associate Professor, Department of Otolaryngology

Cumilla Medical College, Cumilla.

Email: jamdr67@gmail.com.

Mobile +8801711785070

2. Dr. Md. Golam Mustafa

Associate Professor

Department of Otolaryngology

Cumilla Medical College, Cumilla.

3. Dr. AHM Delwar

Associate Professor

Department of Otolaryngology

Cumilla Medical College, Cumilla.

4. Dr. Shazibur Rashid

Associate Professor

Department of Otolaryngology

Cumilla Medical College, Cumilla.

5. Dr. Md. Mostafizur Rahaman

Assistant Professor

Department of Otolaryngology

Cumilla Medical College, Cumilla.

6. Dr. Shamsuddin Ahmed

Assistant Professor

Department of Otolaryngology

Cumilla Medical College, Cumilla.

\section{Introduction}

Nasal septal surgery is one of the most common surgical procedures in otolaryngology ${ }^{1}$. Among the septal surgeries, SMR (submucosal resection of septal bones and cartilages) is the commonest one by which a deviated portion of septal bones and cartilages are removed to make the septum straight and central in the patients of 18 years of age or more. Septoplasty is applied to remove the same as per as minimum keeping the mucoperiosteum \& mucoperichondrium unseparated on one side in the patients of below 18 years of age. It may or may not be associated with turbinate reduction. Bleeding, septal hematoma, septal abscess, septal perforation, adhesion are common postoperative complications of SMR/septoplasty though the incidence is rather low. Among the complications, adhesion (synechia) between the lateral wall and septum is most common. The incidence of it can be reduced by various procedures; intranasal splinting is one of them. The reported frequency of it varies from $6.8-36 \%$. For this reason, since 1955 an intranasal splint has been used ${ }^{4,5}$. Apart from septal surgeries, other intranasal surgeries (FESS, polypectomy, antrostomy) may also result in adhesion formation.

An intranasal splint (INS) is a device that is placed in one or both sides of the septum with the intention of preventing adhesions, hematoma, and perforation, and to facilitate mucosal healing and support tissue alignment ${ }^{1}$. Although their utilization varies between surgeons, and possible side effects include pain, discomfort, and infection they remain a popular perioperative adjunct ${ }^{6}$. INS is available in the market in various forms of various brands. Modern splints are found in a variety of shapes, sizes, and fit with additional features depending on the type of procedure. But it may be made of dental wax or hand-cut piece of X-ray film, coffee cup lid, or intravenous 
fluid bag. It may be removable or absorbable, may be incorporated with nasal airways or magnet ${ }^{7}$. In our study, we used a hand-cut piece of the intravenous fluid bag. In spite of the wide usefulness of intranasal splint as a good intervention to minimum postoperative complications, some recent studies have created considerable doubt in their affectivity and morbidity. To evaluate the benefits and morbidities associated with intranasal splint we conducted our study.

Objectives: To determine the necessity of intranasal splint in nasal septal surgery to prevent the formation of synechia.

\section{Materials and Methods}

This is a randomized control study of 200 patients of SMR/septoplasty, done for nasal septal deviation causing symptoms done in Cumilla Medical College Hospital in the period of January 2016 to December 2019. They were divided into two groups: group-A \& group-B. Group-A comprises the patients with an intranasal splint (INS) and group-B comprises the patients with no intranasal splint (NINS). Each group contains 100 patients. The age of all of the patients was between 13-49 years. Operations were done under general anesthesia with orotracheal intubation. The septum was infiltrated bilaterally in the submucosal and subperiosteal plan with inj. 2\% lidocaine $+0.0005 \%$ adrenaline (Jasocaine-A, Jayson pharmaceuticals 1td, Bangladesh) at the beginning of the operation to aid homeostasis. Through a hemitransfix incision deviated osteochondral parts were removed. The incision was closed with a $3 / 0$ atraumatic catgut. Hypertrophied inferior turbinates of both sides were reduced by surface cautery or submucosal diathermy. No turbinectomy was done. In group-A, an intranasal splint made of a cut piece of sterile I.V. saline bag was molded in both sides of the septum and it was fixed to columella by a mattress suture with the same catgut. Both the nasal cavities were packed by a nasal pack soaked with an ointment of neomycin sulfate \& bacitracin(NUBA, Biopharma Ltd, Bangladesh). After 48 hours it was removed and all the patients were discharged from the hospital with advice to come after 7 days (7th postoperative day). Patients of group-A (INS group) had the intranasal splint in the nasal cavity which removed on 1st follow up visit. All the patients of both groups came to our center for a follow-up visit weekly for 6 weeks and nasal toileting done in every visit. In each follow-up visit nasal toileting was done by electric sucker machine or Tilly,s nasal dressing forceps, and examined for any complication especially adhesion. Adhesions detected in their follow up visits were released under local anesthesia by Tilly,s nasal dressing forceps, or monopolar diathermy. Three patients needed second-time placement of intranasal splinting for 14 days more for a successful recovery. Pain in the postoperative period was analyzed according to visual analog score (VAS) system by asking the patient to score pain from 1-10 and was categorized as follows: mild pain 1-3, moderate pain 4-7 \& severe pain 8-10. In the postoperative period, all the patients have prescribed cefixime (400 mg) bid, flucloxacillin (500mg) q.i.d, paracetamol $(500 \mathrm{mg})$ t.i.d, chlorpheniramine maleate (4mg) t.i.d. In addition to these during their discharge a nasal decongestant drop, Antazol (Xylometazoline hydrochloride $0.1 \%$, square pharmaceuticals Ltd, Bangladesh), and liquid paraffin were added to install 3-4 drops in each nasal cavity three times daily for 7 days.

All the patients with deviated septum with hypertrophy of one or both inferior turbinates were included in our series. Patients with a nasal polyp, tumor, chronic sinusitis, diabetes, hypertension, previous history of nasal surgery were excluded.

Table-I: Age distribution.

\begin{tabular}{lcccc}
\hline Age in year & \multicolumn{2}{c}{ INS (group-A);n=100 } & \multicolumn{2}{c}{ NINS (group-B);n=100) } \\
\hline \multirow{2}{*}{$10-20$} & Number & Percentage & Number & Percentage \\
$21-30$ & 25 & $25 \%$ & 22 & $22 \%$ \\
$31-40$ & 45 & $45 \%$ & 48 & $48 \%$ \\
$41-50$ & 26 & $26 \%$ & 25 & $25 \%$ \\
\hline
\end{tabular}

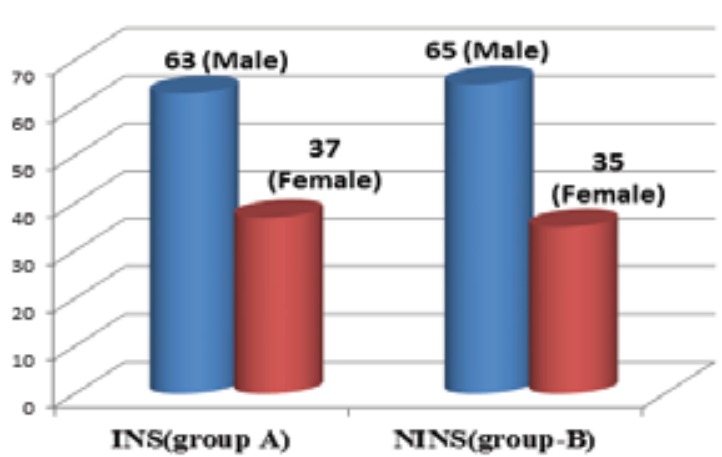

Figure-1: Sex distribution.

Table-II: Frequency of synechia formation

\begin{tabular}{lcc}
\hline Adhesion formation & Number & Percentage \\
\hline INS (group-A); $=100$ & 04 & $04 \%$ \\
NINS (group-B);n=100 & 06 & $06 \%$ \\
\hline
\end{tabular}

Table-III: Incidence of co-morbidities.

\begin{tabular}{lcccc}
\hline Age in year & \multicolumn{2}{c}{ INS (group-A); $\mathbf{n = 1 0 0}$} & \multicolumn{2}{c}{ NINS (group-B); $\mathbf{n = 1 0 0 )}$} \\
\hline & Number & Percentage & Number & Percentage \\
Pain/headache & 26 & $26 \%$ & 05 & $05 \%$ \\
Vestibulitis & 17 & $17 \%$ & 04 & $04 \%$ \\
Fainting during & 06 & $06 \%$ & 00 & $00 \%$ \\
splint removal & & & & \\
Nasal obstruction & 38 & $38 \%$ & 17 & $17 \%$ \\
Anxiety of splint & 35 & $35 \%$ & 00 & $00 \%$ \\
removal & & & &
\end{tabular}

Table-IV: Time of synechia formation.

\begin{tabular}{lcc}
\hline Synechia & NS (group-A);n=100 & NINS (group-B);n=100 \\
\hline $1^{\text {st }}$ week & 00 & 00 \\
$2^{\text {nd }}$ week & 01 & 02 \\
$3^{\text {rd }}$ week & 02 & 02 \\
$4^{\text {th }}$ week & 00 & 01 \\
$5^{\text {th }}$ week & 01 & 00 \\
$6^{\text {th }}$ week & 00 & 01 \\
Total & 04 & $\mathbf{0 6}$ \\
\hline
\end{tabular}




\section{Results}

The age of our patients was ranged from 13-49 years with mean age 22.45year. Male to female ratio is $1.78: 1$. Synechia was found in $4 \%$ of the INS group (group-A) and $6 \%$ of the NINS group (group-B). Among the co-morbidities detected in our study pain in nose, face, and the head was $26 \%$ in the INS group and $05 \%$ in the NINS group. Faint during removal of nasal splint $(6 \%)$ and anxiety of splint removal in the postoperative period $(35 \%)$ were two additional terrible conditions found in INS group. Nasal obstruction was found $38 \%$ in the INS group and $17 \%$ in the NINS group. Vestibulitis noted in $17 \%$ of splinted patients and $04 \%$ in non splinted patient.70\% (7/10) synechia was formed in 2 nd and $3 \mathrm{rd}$ week of the postoperative period.

\section{Discussion}

In our study, there was a higher incidence of adhesion in the non-intranasal splint (NINS) group. But in comparison to the intranasal splint (INS) group, the difference was not significant and this may be due to intra-operative surgical technique or post-operative nasal toileting to prevent crust formation which leads to the formation of adhesion. We found the formation of adhesion in the non-intranasal splint (NINS) group was 6\% and in the intranasal splint (INS) group was 4\% (Table-II). This result is comparable to other studies.

Von Schoenberg $M$ et $\mathrm{al}^{8}$ found that frequency of formation of adhesion in the splinted and non splinted group was low and almost the same $(2 \%)$ in their 105 patient series. Pringle $\mathrm{MB}^{9}$ carried out a survey on 440 consultants on the same issue and found that $33 \%$ of them never or rarely used intranasal splint and reported an adhesion rate of 5.2\% NINS group and 3.9\% in INS group and they commented it as non-significant. Malki D et al ${ }^{10}$ showed no statistically significant difference in the incidence of adhesions between the splinted and non-splinted patients. Follow up after 6 weeks of their surgeries the incidence of adhesion in the splinted group was $1.8 \%(1 / 55)$ and in non splinted group was $7.7 \%$ (4/52). Their opinion was no significant difference in the incidence of adhesions between the splinted and non-splinted groups. They concluded that the morbidity associated with nasal splints does not justify their use in routine nasal surgery if the aim is to prevent septal adhesion. Cook JA et $\mathrm{al}^{4}$ showed a failure of intranasal splints in preventing intranasal adhesion $(6.5 \%$ in splinted vs. $7.0 \%$ in non splinted group) and concluded that there is no clear advantage of using intranasal splints and they should, therefore, be used sparingly and recommended use of nasal toilet after septal surgery. Study of Almoflehi $\mathrm{MS}^{11}$ also concluded that the intranasal splints are not of significant value in preventing nasal adhesion $(10 \%$ in splinted vs. $21 \%$ in non splinted group) and the recommendation was that the use of intranasal splints in septal surgery has to be individualized. Almagro KS et al ${ }^{12}$ in their study found no significant difference in the incidence of adhesion formation between splinted and non splinted groups ( $2 \%$ in splinted vs. $10 \%$ in non splinted group).

On the other hand contrary to our results Campbell et a ${ }^{13}$ inserted a nasal splint into one side of the nose of 106 patients undergoing a variety of intranasal procedures. All adhesions occurred on the non splinted side and were more common when bilateral nasal wall procedures had been performed $(8 \%$ in splinted versus $26 \%$ in non-splinted). They concluded that splints were justified for bilateral wall procedures but their increased morbidity did not justify their use in single wall procedures. Von Schoenberg et $\mathrm{al}^{7}$ found a low incidence of adhesions in the first-week postoperatively when intranasal splints were used and found that the highest incidence of intranasal adhesions occurred in non splinted patients who had surgery to both walls of the nasal cavity $(3.6 \%$ in splinted vs. $31.6 \%$ in non splinted). Roberto et $\mathrm{al}^{14}$ found nasal splints very effective in preventing adhesion formation in patients undergoing septoplasty with turbinectomy. They found no adhesion in the splinted group but $10.6 \%$ in the non splinted group. Nabil-ur-Rahman $\mathrm{MA}^{15}$ concluded that complications were related to the type of procedure being performed and adhesions were common complications if intranasal splint were not provided. Roberto et $\mathrm{al}^{14}$ shows that the nasal splint increases co-morbidities such as pain and discomfort in the post-surgical period. On the other hand, it presented high efficiency to prevent post-surgical synechias. According to Vanita Sarin et al ${ }^{16}$ INS had a significant role in preventing intranasal adhesions but it definitely increases morbidity by causing pain, discomfort, and crust formation. On the basis of their study, they recommended intranasal splints especially in those surgeries in which both lateral walls of nose and septum are simultaneously manipulated. Kashif Mahmood et $\mathrm{al}^{18}$ found septal adhesion 3.1\% in the splinted group and 3.8\% in non splinted group.

Among the co-morbidities, pain in the nose, face, or head in the postoperative period is the most distressful factor associated with a nasal splint (Table-III). We noted it $26 \%$ in INS and $5 \%$ in the NINS group. In the INS group, $42.30 \%(11 / 26)$ complained of mild, $50 \%(13 / 26)$ moderate, and $7.70 \%(2 / 26)$ severe pain in their 1 st week of the postoperative period. Some studies also found almost the same result of INS related pain ${ }^{4,14,16}$. Vestibulitis or tip cellulitis due to persistent irritation by a sharp margin of the splint is another afflicted condition in the INS group and we found it $17 \%$ in the splinted group and $04 \%$ in non splinted group. Cook JA et $\mathrm{a}^{14}$ found it $6.5 \%(3 / 46)$ in their splinted group and none in the non splinted group. This high incidence may due to the use of a hand-cut device. Anxiety for splint removal (35\%) and being fainted during splint removal $(06 \%)$ in the INS group were another two distressful conditions in our study. Nasal obstruction is due to the formation of a mound with crust, old clotted blood, and natural nasal discharge, and it was found in both the groups but more with a splinted group (38\%) as there was an additional foreign body (splint). It is and $17 \%$ in the non-splinted group.

The routine use of nasal splints in SMR/septoplasty patients is still a matter of debate. Splints add significant pain and discomfort in the postoperative period ${ }^{19,20}$. Patient with INS passed their post-operative period with the 
anxiety of splint removal. It is recommended that their use should be individualized depending upon the procedure being performed. They are more justified when surgical procedures are performed on both medial and lateral walls of nose simultaneously ${ }^{13,16,17}$.

\section{Conclusion}

An intranasal splint is widely acceptable to decrease the incidence of intranasal adhesion. But considering other co-morbidities the routine use of the intranasal splint can no longer be justified when the same effects can be achieved by careful nasal toileting. An intranasal splint can be recommended in those surgeries in which both nasal wall and septum are manipulated simultaneously. Regular outpatient follow-up with suction toileting are very effective in preventing adhesion formation.

Conflict of Interest: None.

\section{Acknowledgment}

We are grateful to Dr. Rafiqul Islam Sarker, Associate Professor (ENT) and Vice-Principal of Cumilla Medical College for his kind and continuous support and inspiration beyond our work.

\section{References}

1. Jung YG, Hong JW, Eun YG, Kim MG. Objective usefulness of thin silastic septal splints after septal surgery. Am J Rhinol Allergy. 2011; 25: 182- 185.

https://doi.org/10.2500/ajra.2011.25.3584

PMid:21679530

2. White A, Murray JA. Intranasal adhesion formation following Surgery for chronic nasal obstruction. Clin Otolaryngol Allied Sci.1988; 13:139-143.

https://doi.org/10.1111/j.1365-2273.1988.tb00754.x

PMid:3416505

3. Shone GR, Clegg RT. Nasal adhesions. J Laryngol Otol. 1987; 101: 555-557.

https://doi.org/10.1017/S0022215100102233

PMid:3598355

4. Cook JA, Murrant NJ, Evans KL, Lavelle RJ. Intranasal splints and their effects on intranasal adhesions and septal stability. Clin Otolaryngol Allied Sci. 1992; 17: 24-27.

https://doi.org/10.1111/j.1365-2273.1992.tb00982.x

PMid: 1555312

5. Dubin MR, Pletcher SD. Postoperative packing after septoplasty: Is it necessary? Otolaryngol Clin North Am. 2009; viii-ix, 42:279-285.

https://doi.org/10.1016/j.otc.2009.01.015

PMid: 19328892

6. Tang S, Kacker A. Should intranasal splints is used after nasal septal surgery? Laryngoscope. 2012; 122(8): 1647-8.

https://doi.org/10.1002/lary.23324

PMid:22833305

7. Lau, H A Elhassan, N Singh. History of intranasal splints. J The Journal of Laryngology \& Otology. 2018; 132: $189-201$.
https://doi.org/10.1017/S0022215118000142

\section{PMid:29380712}

8. Von Schoenberg M, Robinson P, Ryan R. The morbidity from nasal splints in 105 patients. Clin Otolaryngol Allied Sci. 1992; 17: 528-530.

https://doi.org/10.1111/j.1365-2273.1992.tb01712.x

\section{PMid:1493631}

9. Pringle MB. The use of intra-nasal splints: A consultant survey. Clin Otolaryngol Allied Sci. 1992; 17: 535-539.

https://doi.org/10.1111/j.1365-2273.1992.tb01714.x

PMid:1493633

10. Malki D, Quine SM, Pfleiderer AG. Nasal splints revisited. J Laryngol Otol. 1999; 113: 725-727.

https://doi.org/10.1017/S0022215100145037

\section{PMid: 10748847}

11. Almoflehi MS. The impact of using intranasal splints on morbidity and prevalence of adhesions. J Sc Tech. 2009; 10: 1-6.

12. Al-Mazrou KA, Zakzouk SM. The impact of using intranasal splints on morbidity and prevalence of adhesions. Saudi Medical Journal. 2001; 22 (7): 616-618. 13. Campbell JB, Watson MG, Shenoi PM. The role of intranasal splints in the prevention of postoperative nasal adhesions. J Laryngol Otol. 1987; 101:1140-1143.

https://doi.org/10.1017/S0022215100103391

PMid:3694030

14. Roberto G, Fabiano H, Maria R. Frequency of nasal synechiae after septoplasty with turbinectomy with or without the use of a nasal splint. Arch Otolaryngol. Sao Paulo. 2008; 12: 24-7.

15. Nabil ur Rahman MA. Complications of surgery for a deviated septum. JColl Physicians Surg Pak. 2003; 13: 565-8.

16. Vanita Sarin, Baldev Singh, Vanika Anand, Jaskaram Singh Gill. Nasal splints after routine nasal surgery: How justified is it? Pak j otolaryngol. 2013; 29: 22-24.

17. Tarique Ahmed Maka, Zafarullah Khan, Usman Akhtar, Bilal Akram, Mubashir Iqbal. Role of intranasal splints in preventing postoperative nasal mucosal adhesions. Pak Armed Forces Med J. 2018; 68 (1): 101-05 18. Kashif Mahmood, Mirza Nasheed Baig, Nayyer Ayub, Tabassum Aziz. Efficacy of nasal splints in reducing the incidence of intranasal adhesions following septoplasty. JIIMC. 2016; 11(1): 8-10.

19. Osama G., Abdel-Naby, Awad Khalf, A. Hamid. The Value of Intranasal Splints After Partial Inferior Turbinectomy. Indian J Otolaryngol Head Neck Surg.

Jan-Mar 2015; 67(1): 75-80.

https://doi.org/10.1016/j.intermet.2015.07.015

20. Aksoy E, Serin GM, Polat S, Kaytaz A. Removing intranasal splint after septal surgery. The journal of craniofacial surgery. 2011; 22(3):1008-1009.

https://doi.org/10.1097/SCS.0b013e318210163e

PMid:21558898 